\title{
Research on the Phase Change Solar Energy Fresh Air Thermal Storage System
}

\author{
Guohui Feng $^{1}$, Lei Zhao ${ }^{1}$, Yingchao Fei ${ }^{1}$ and Kailiang Huang ${ }^{2}$ \\ 1. School of Municipal and Environmental Engineering, Shenyang Jianzhu University, Shenyang 110168, China \\ 2. Faculty of Urban Construction and Environmental Engineering, Chongqing University, Chongqing 400030, China
}

Received: August 16, 2013 / Accepted: September 27, 2013 / Published: February 28, 2014.

\begin{abstract}
In this article, a new kind of solar fresh air system is designed in order to realize the improvement of thermal efficiency by the integrated application of the PCMs and heat pipe technology. Under the adequate sunshine condition, the fresh air is directly delivered into the indoor environment after being heated by the solar collector. When the sun radiation is reduced, the heated air temperature can not satisfy the need of supply of air temperature.The main heat source is changed to phase change heat storage equipment instead of solar energy. The system adopt heat pipe for a high-efficiency and isothermal heat transfer which recover the shortcomings of PCMs such as: low coefficient of thermal conductivity and poor thermal efficiency. This article establishes the physical model of phase change solar energy fresh air thermal storage system and creates the mathematical model of its unsteady heat transfer to simulate and analyse the operation process by using Fluent software. The results of the study show that, compared to normal fresh air system, the phase change solar energy fresh air thermal storage system has a significant improvement in energy saving and indoor comfort level and will play an important role in the energy sustainable development.
\end{abstract}

Key words: Solar fresh air system, heat pipe, phase change thermal storage, simulation analysis.

\section{Introduction}

The problem of improving energy efficiency and completing the transformation of the traditional energy to green energy is the current research focus, in order to achieve the target of reducing energy consumption and improve the quality of life. A new kind of phase change solar energy fresh air thermal storage system is the ability to achieve air supply of new air after double efficient heating by simulation.

In the north cold regions, the average outdoor temperature in winter is often in $-10{ }^{\circ} \mathrm{C}$ to min $20^{\circ} \mathrm{C}$ due to requirements of energy saving, so sealing requirements of doors and windows is increasing. Meanwhile, in order to ensure the requirement of indoor temperature in winter, interior doors and windows often closed, air does not flow well. Although

Corresponding author: Guohui Feng, professor, research fields: building energy efficiency, phase change energy storage. E-mail: fengguohui888@163.com. the temperature reaches the heating requirements of design, from the comfort point it is not conducive to people's health. In the fenestration behavior research on cold area in winter in 2013, statistics show that $80 \%$ of residents are willing to open windows for ventilation when heating temperature is not enough while residents choosing not to open the window for other reasons account for $20 \%$ (Fig. 1). This shows that people still hope for a certain number of windows open for ventilation every day to improve air quality in the living room.

Per capita area of residence is usually larger currently, so the design is usually selected the number of ventilators 0.3 times one hour according to winter fresh air ventilation standards, considering the requirements of energy conservation and the new air requirements. Indoor fresh air ventilation is usually taken $25 \mathrm{~m}^{2}$ /(h-person). But the actual situation and the design requirements are usually not the same, people 


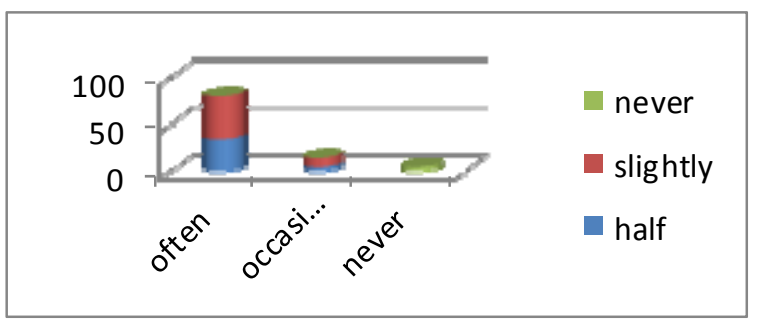

Fig. 1 Statistics of research results.

will open the window for short indoor ventilation in a period of time. Before leaving the room or indoor room there exists a peculiar smell so that people falls far short of the time to improve indoor air quality.

Solar new air technology is already very mature, running to achieve an average of more than $75 \%$. In the sunny day, good solar radiation solar new air system can go from $60 \%$ to $75 \%$ of solar energy, transformed by the light and heat of the collector plate, and the general air temperature will rise $15{ }^{\circ} \mathrm{C}$ to $40{ }^{\circ} \mathrm{C}$, which is higher than the indoor temperature, and can be directly used for the indoor ventilation. Outdoor fresh air enters from the air intake and is heated by the collector plate. It reaches the highest temperature on the top, then is pumped into the heat transfer equipment to heat up again and sent into the room [1-3].

However, due to the heat extraction and storage of the system with air as the medium, this traditional convective heat transfer constrained by convection coefficient, medium flow velocity factors, the overall efficiency will decline, and will inevitably need to increase the volume of heat transfer equipment to reach the heat exchanger requirements, which will sacrifice interior space, while the low temperature of new air also seriously increases building energy consumption [4].

\section{The Phase Change Solar Energy Fresh Air Thermal Storage System}

Based on the above problems, innovation lies in the design of new air system described. In this article heat pipe is selected as a heat transfer means, and phase change energy storage apparatus as a secondary heat source ensures the thermal comfort of new air room. The basic working principle is shown in Fig. 2.

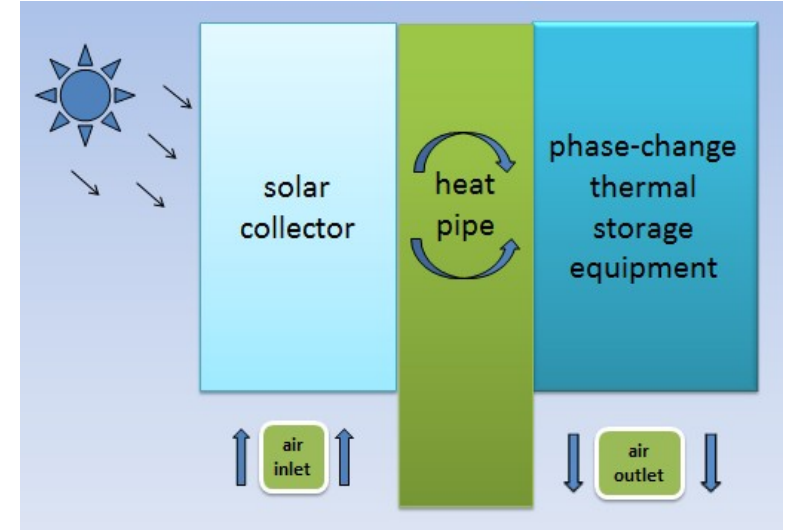

Fig. 2 Working principle.

The heat transfer of the heat pipe portion is shown in Fig. 3. The fluid in the tube shell absorbs heat and vaporizes in the form of steam, and transfers through wick from one heated end to the other. After condensation in the other end, liquid fluid flows back to the evaporator section. The process completes an endothermic and exothermic cycle with the help of spontaneous capillary forces.

The advantages of heat pipe are:

(1) Fast heat conduction speed, high strength, high efficiency, heat conduction can even reach to velocity of sound;

(2) Good isothermal: Pass a lot of heat in a small temperature difference and heat transfer resistance is small;

(3) The safety reliability: There is no overpressure in the pipe, no need to worry about dry burning. After the vaporization of the working fluid, the inner pressure of the heat pipe will not change with temperature change;

(4) Reversibility of the direction of heat flow: Due to its internal cycle power is the capillary force, either end heated can be the evaporating section, and the other end outwardly heat dissipation will be the condensation section.

The studies show that in the case without efficient heat transfer thermal device, even if the weather is sunny and solar radiation is sufficient, fresh air, only after it warms up solar energy new air collector and then is directly sent into the room, only one hour time around 1:00 does not increase the indoor heat load, and 


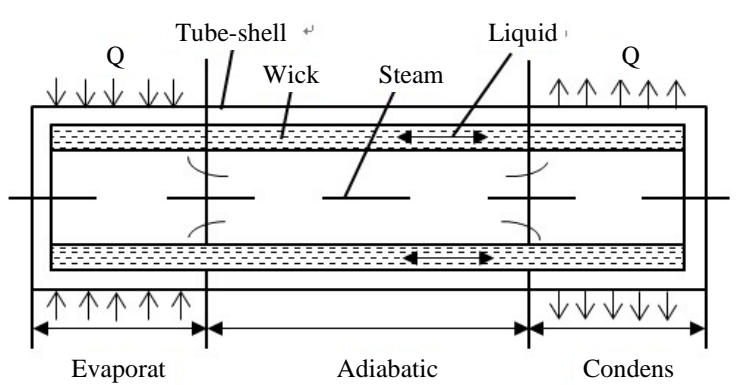

Fig. 3 Heat pipe working principle.

the rest of the time causes the indoor temperature fluctuations [5-7].

This structure of phase change solar energy fresh air thermal storage system is shown in Fig. 4. The inside part of the device according to the design position of heat pipe fixing the phase change material and heat pipe to a rectangular baffle shape, divides the space into a serpentine flow channel (Fig. 5), the working principle is: with the gradual increase of the solar radiation, the temperature of the collector plate is rising; the heat is gathered in the heat collecting plate when the new air is heated, at the same time the heat pipe isothermal pass for the heat accumulator of phase change material; fresh air is leaded into the heat exchanger equipment through the fan and flows in the flow channel; make the heat transfer with the phase change material and send into the interior through the outlet. When solar radiation weakened, the temperature of the heat pipes is lower than that at the phase change material melting point. The phase change material exothermic heat fresh air as the primary heat source. New air continued heated reservoir until the heat in phase change material is released all, and this system prolonged the time of ventilation. Compared with traditional air heating phase change materials, it enhances efficiency obviously and weather fluctuations will not affect the fresh air heat exchanger, guarantee the stability of the indoor temperature and maximum the human comfort $[8,9]$.

\section{Simulation Calculation}

For the above system, using the Fluent software simulates the following four conditions:

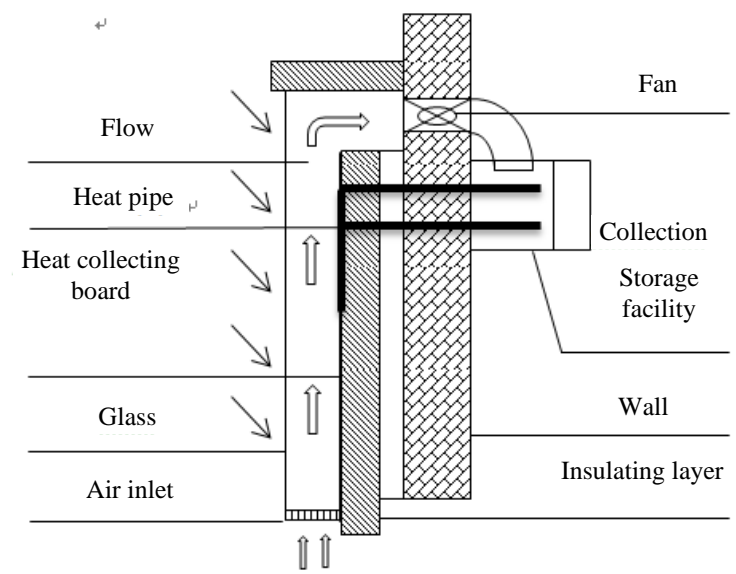

Fig. 4 System structure diagram.

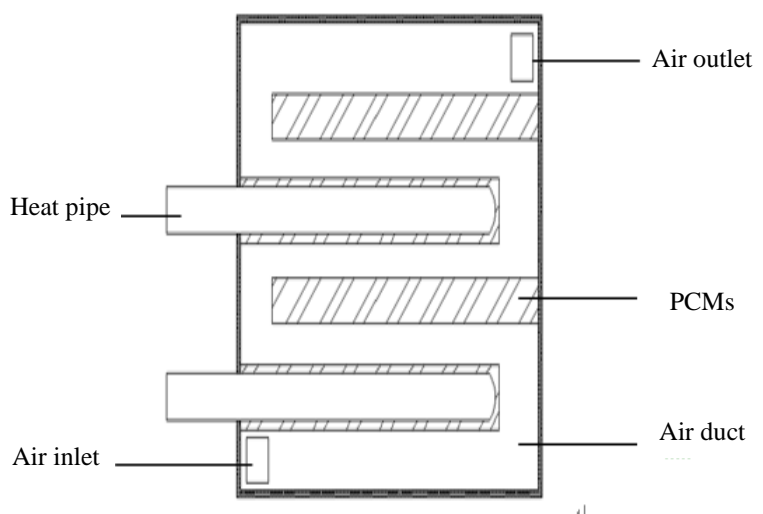

Fig. 5 Equipment internal structure.

Condition 1: Time periods ranging from 9:00 a.m. to 11:00 a.m., average solar radiation intensity is about $305.56\left(\mathrm{~W} / \mathrm{m}^{2}\right)[10]$. At this time the whole system is in the warm-up phase. Heat of collector panels is extracted from the heat pipe evaporator section unable to reach the phase transition point of the phase-change material, and it does not make indoor ventilation. Outdoor air temperature increases after going through collector plates and heat transfer equipment, but does not reach the ventilation standards. The results of simulation show that heat collecting on the collector plate is less in this time period, secondary heating effect of heat transfer equipment is not obvious, and new air is unable to meet the minimum supply air temperature through heat exchanger. At this time heat exchanger equipment is in the warm-up phase state (Fig. 6).

Condition 2: From 11:00 a.m. to 14:00 p.m., in the strongest period of solar radiation, solar radiation 

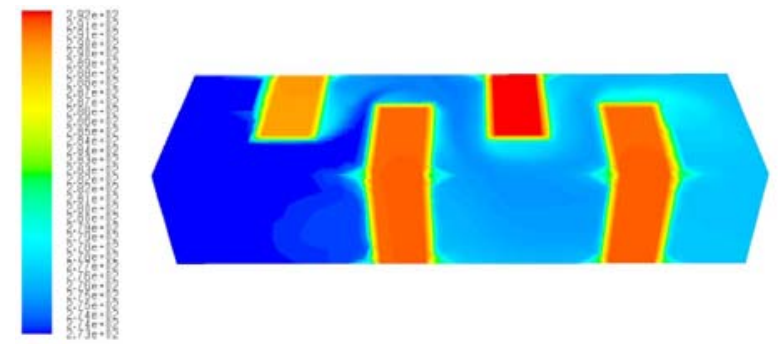

Fig. 6 Warm-up phase of the heat transfer equipment.

intensity reached the peak of $396.30\left(\mathrm{~W} / \mathrm{m}^{2}\right)$ when the temperature of collector plate is much higher than the phase transition point temperature [11]. The heat pipe efficient spread heat of the collector plate to the phase change material, then phase change material storing heat. While excess heat continues to transfer to the new air in the flow channel through phase change materials, the temperature of secondary heating new air has reached the blast standard and sent into the interior for ventilation. The results of simulation show that heat collected from the collector plates reaches the maximum, the highest temperature of new air in the air collector is more than $50^{\circ} \mathrm{C}$. With efficient heat transfer through the heat pipe, sufficient heat can be supplied to the heat transfer equipment. At this time new air temperature inside the device has exceeded the minimum supply air temperature, and can be directly sent into the interior (Fig. 7).

Condition 3: From 14:00 p.m. to 16:00 p.m., average solar radiation intensity is about $208.33\left(\mathrm{~W} / \mathrm{m}^{2}\right)$. At this time solar radiation weakened stage, after efficient heat storage in the two hours at noon, phase change material has been completely filled with the heat. With the weakening of the solar radiation, the temperature of the collector plate has dropped. When the temperature is reduced to less than the phase transformation point, the heat pipe is no longer available to conduct heat to the heat storage device. At this time secondary heat to heat the new air is completely from the phase change material in the noon. Without this equipment, only relying on solar air collector for new air heating, the fresh air can not be directly sent into the room, because the new air temperature is lower than the indoor heating temperature and after efficient heat the phase
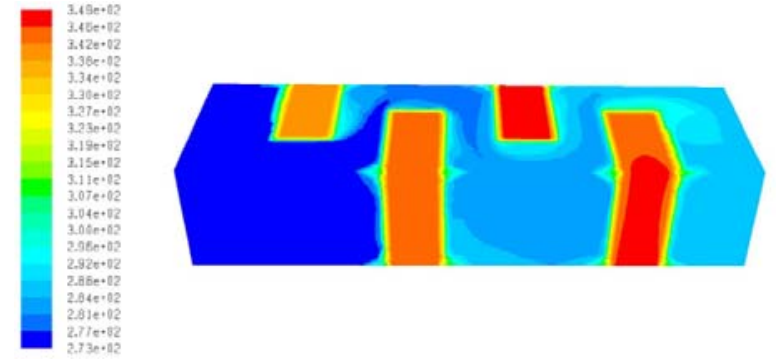

Fig. 7 Strongest stage of effect of heat transfer in heat transfer equipment.

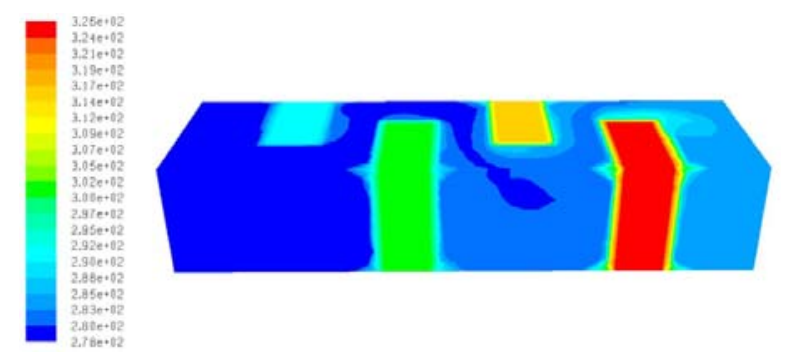

Fig. 8 Exothermic initial stage of heat transfer equipment.
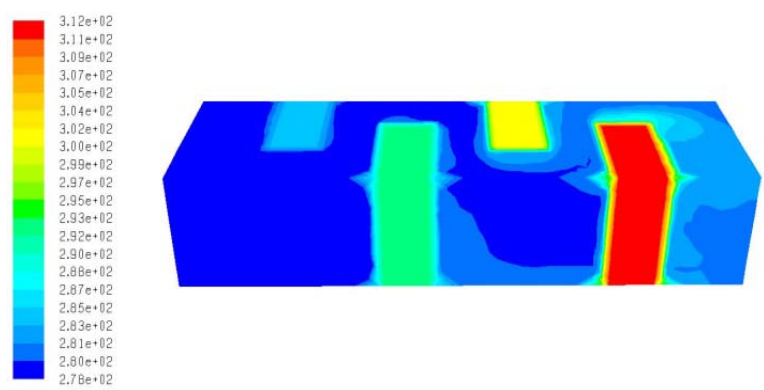

Fig. 9 End stage of exothermic process.

changematerial has overcome itself shortcomings of low heat transfer coefficient, it has the ability to fill the heat in a short period of time, extend time for ventilation and improve the indoor air quality [12] (Fig. 8).

Condition 4: From 16:00 p.m. to 18:00 p.m., heat storage in the phase change material will gradually release completely, and temperature of new air is gradually reduced too. The system will shut down after being reduced to indoor heating temperature, when indoor temperature remains in the heating temperature, so it will not cause the indoor temperature fluctuations for ventilation and will not affect the indoor normal life, thus avoiding the discomfort situation caused by the windows open for ventilation [13] to improve air quality (Fig. 9). 


\section{Conclusions}

Through research statistics, we get the actual situation of the average residential indoor ventilation in cold regions in winter, learning that low outdoor ambient temperature and other reasons force people to reduce the ventilation. And there is a widespread dissatisfaction with the low air quality of indoor which is caused by lack of air circulation. In order to improve residential air quality and improve the indoor comfort, the article designs a phase change solar energy fresh air thermal storage system. Through the initial simulation, it is found that this system can extend ventilation time without increasing winter residential heating load, and an entirely new way is proposed in order to think about fresh air ventilation in cold regions.

\section{Acknowledgments}

This study is supported by the National High-Tech Research and Development Program of China (2012AA052503-5).

\section{References}

[1] B.M. Ramani, A. Gupta, R. Kumar, Performance of a double pass solar air collector, Solar Energy 84 (11) (2010) 1929-1937.

[2] M. Baritto, J. Bracamonte, A dimensionless model for the outlet temperature of a no isothermal flat plate solar collector for air heating, Solar Energy 86 (1) (2012)
647-653.

[3] E. Bilgen, B.J.D. Bakeka, Solar collector systems to provide hot air in rural applications, Renewable Energy 33 (7) (2008) 1461-1468.

[4] T. Kousksou, F. Strub, J.C. Lasvignottes, A. Jamil, J.P. Bédécarrats, Second law analysis of latent thermal storage for solar system, Solar Energy Materials and Solar Cells 91 (14) (2007) 1275-1281.

[5] N.K. Bansal, D. Buddhi, Performance equations of a collector cum storage system using phase change materials, Solar Energy 48 (3) (1992) 185-194.

[6] B. Chen, J. Chen, Study on control strategy for solar air collector integrated with building, Renewable Energy 31 (4) (2010) 418-423.

[7] G.A. Gan, Parametric study of trombe walls for passive cooling of buildings, Energy and Buildings 27 (1) (1998) 37-43.

[8] M. Sandberg, B. Moshfegh, Investigation of fluid flow and heat transfer in a vertical channel heated from one side by PV elements, Part II-Experimental study, Renewable Energy 8 (1-4) (1996) 57-63.

[9] B. Mosh, M. Sandberg, Investigation of fluid flow and heat transfer in a vertical channel heated from one side by PV elements, Part I-Numerical study, Renewable Energy 8 (1-4) (1996) 349-357.

[10] Z. Yang, X. Xu, Analysis on the temperature field of trombewall, Journal of Engineering Thermo Physics 27 (4) (2006) 568-570.

[11] J. Ren, Solar Energy Technology, Beijing Science Press, China, 2008, pp. 13-16.

[12] F.K. Forson, M.A.A. Nazha, Experimental and simulation studies on a double duct solar air heater, Energy Conversion and Management 44 (8) (2003) 1209-1227.

[13] S.O. Enibe, Thermal analysis of a natural circulation solar air heater with phase change material storage, Renewable Energy 28 (14) (2003) 2269-2299. 